\title{
EFFECTS OF COMORBIDITIES ON THE ELDERLY PATIENTS WITH COVID-19: CLINICAL CHARACTERISTICS OF ELDERLY PATIENTS INFECTED WITH COVID-19 FROM SICHUAN, CHINA
}

\author{
S.-P. DAI ${ }^{1}$, X. ZHAO ${ }^{2}$, J.-H. WU ${ }^{1}$ \\ 1. National Center for Geriatrics Clinical Medicine Research, Department of Geriatrics and Gerontology, West China Hospital, Sichuan University, Chengdu, China; 2. The Public

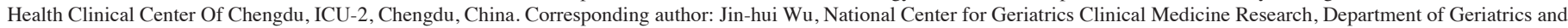 \\ Gerontology, West China Hospital, Sichuan University, Chengdu, 610041, China, wujinhui@scu.edu.cn
}

\begin{abstract}
Objectives: The co-occurrence of chronic diseases in the elderly is a common problem. However, the relationship between comorbidities and the prognosis of elderly patients with COVID-19 was not clear. This study was supposed to describe the clinical characteristics of elderly patients with COVID-19 infection from Sichuan province and the effects of comorbidity. Design: A retrospective study. Settings and participants: COVID-19 patients from Public Health Clinical Center of Chengdu between December 16, 2019 and February 26, 2020 were included in this study. Patients were divided into elderly group ( $\geq 60$ years old) and non-elderly group ( $<60$ years old). Results: Elderly patients with COVID-19 indicated relatively higher proportion of comorbidities, and the most common were atherosclerotic cardiovascular disease (56.5\%), hypertension (43.5\%) and chronic pulmonary disease $(21.7 \%)$. The proportion of severe cases was higher in elderly group than that in non-elderly group $(73.9 \%$ and $42.2 \%$, respectively, $\mathrm{P}=0.012)$. During hospitalization, elderly patients indicated relatively higher proportion of complications, such as shock $(21.7 \%)$, respiratory failure $(21.7 \%)$. The proportion of patients with a decreased number of CD8+ lymphocytes $(82.6 \%)$ and B lymphocytes $(77.8 \%)$ in elderly patients was significantly higher than that in non-elderly group (48.9\% and 44.8\%, respectively). All 3 deaths were elderly patients with comorbidities and the cell counts of T lymphocyte subsets, B and NK cells of them were significantly decreased at admission. Conclusions: Elderly patients with COVID-19 had a high proportion of severe cases and comorbidities, more likely to show low immune function, and indicate higher proportion of complications.
\end{abstract}

Key words: COVID-19, comorbidities, elderly, clinical characteristics, Sichuan Province.

\section{Introduction}

In December 2019, pneumonia of unknown cause broke out in Wuhan, China (1). The pathogen has been identified and was named as «COVID-19» in February 11, 2020 (2). Older populations are more susceptible to variety of diseases compared to younger, including COVID-19 infection $(3,4)$. Although the entire population is susceptible to the COVID-19, older patients had higher morbidity and case-fatality rate (5). The mortality rate $(4.5 \%)$ of the people over 60 years old was much higher than that of the people under 60 years old $(1.4 \%)$ (6). The co-occurrence of chronic diseases in the elderly is a common problem in the field of global public health (7). It was reported that more than half of the elderly in developed countries had more than three chronic diseases, meaning an individual suffers from two or more diseases with different pathology and no mutual dependence at the same time $(8,9)$. Studies in China such as Beijing and Shanghai suggest that more than 70 percent of elderly people in the community have two or more chronic diseases $(10,11)$. Compared with patients with a single disease, the hospitalization rate and fatality rate of patients with comorbidities are higher, and the clinical prognosis is significantly poor. However, the relationship of comorbidities and the prognosis of elderly patients with COVID-19 was not clear. Therefore, this study intended to describe the clinical characteristics of elderly patients with
COVID-19 infection and the effects of comorbidity by comparing with non-elderly patients.

\section{Methods}

\section{Participants}

We retrospectively reviewed the medical records of patients COVID-19 who were hospitalized at Public Health Clinical Center of Chengdu, from December 16, 2019 to February 26, 2020. All confirmed cases were diagnosed as having 2019-nCoV pneumonia according to WHO interim guidance (12). Mild cases were defined as confirmed cases with fever, respiratory symptoms and radiographic evidence of pneumonia. Severe cases were defined as mild cases with one of the following conditions: (1) respiratory rate $\geq 30$ times/ min; (2) oxygen saturation $\leq 93 \%$ in resting state; (3) arterial oxygen partial pressure $(\mathrm{PaO} 2)$ / oxygen concentration $(\mathrm{FiO} 2)$ $\leq 300 \mathrm{mmHg}$; (4) respiratory failure occurs and mechanical ventilation is required; (5) shock occurs; (6) other organ failure occurs and intensive care unit is required. Our study was approved by the ethics committee of West China hospital (No.2020/430) and the written informed consent was waived.

\section{Materials}

The data on demographic, epidemiological, clinical, imaging and laboratory results, outcomes of patients included in this 
THE JOURNAL OF NUTRITION, HEALTH \& AGING

Table 1

Baseline and clinical characteristics of COVID-19 patients

\begin{tabular}{lccc}
\hline Characteristics & Non-elderly patients & Elderly patients & P value \\
\hline Age, years & $41(31.5-49)$ & $73(64-81)$ & 0.201 \\
Sex & & & \\
Men & $26(57.8 \%)$ & $9(39.1 \%)$ & \\
Women & $19(42.2 \%)$ & $14(60.9 \%)$ & 0.169 \\
History of contact & $43(95.6 \%)$ & $19(82.6 \%)$ & 0.017 \\
Comorbidities & $23(51.1 \%)$ & $19(82.6 \%)$ & 0.003 \\
Hypertension & $4(8.9 \%)$ & $10(43.5 \%)$ & 0.464 \\
Diabetes & $5(11.1 \%)$ & $6(26.1 \%)$ & 0.005 \\
Cardiovascular disease & $9(20.0 \%)$ & $13(56.5 \%)$ & 0.003 \\
Chronic pulmonary disease & $0(0.0 \%)$ & $5(21.7 \%)$ & 0.409 \\
Liver disease & $6(13.3 \%)$ & $1(4.3 \%)$ & 0.109 \\
Chronic kidney disease & $1(2.2 \%)$ & $3(13.0 \%)$ & \\
Signs and symptoms & & & 0.522 \\
Fever & $38(84.4 \%)$ & $18(78.3 \%)$ & 0.364 \\
Cough & $34(75.6 \%)$ & $14(60.9 \%)$ & 0.750 \\
Sputum production & $8(17.8 \%)$ & $5(21.7 \%)$ & 0.656 \\
Myalgia or fatigue & $4(8.9 \%)$ & $1(4.3 \%)$ & 1.000 \\
Dyspnoea & $3(6.7 \%)$ & $1(4.3 \%)$ & 0.584 \\
Chills & $3(6.7 \%)$ & $1(4.3 \%)$ & 0.281 \\
Temperature & $37.12( \pm 0.62)$ & $36.95( \pm 0.59)$ & 0.526 \\
Heart rate & $89.44( \pm 13.67)$ & $87.09( \pm 15.85)$ & 0.778 \\
Respiratory rate & $20.93( \pm 2.88)$ & $20.74( \pm 2.22)$ & \\
\hline
\end{tabular}

study were collected. All patients were categorized into two groups according to the age, the elderly group ( $\geq 60$ years old) and the non-elderly group ( $<60$ years old). All collected data were compared between the two groups.

\section{Statistical analysis}

All data were analyzed using the software SPSS version 20.0. Continuous measurements were represented as mean $(\mathrm{x} \pm \mathrm{s})$ and analyzed by t-test or median (P25 and P75) and analyzed by Mann-Whitney $U$ test. $\chi 2$ test were used to analyze the classified variables. P value $<0.05$ was considered to define statistical significance.

\section{Results}

The clinical and laboratory characteristics of elderly patients

68 patients who confirmed with COVID-19 infection were included in this study, aged from 19 to 88 years, and $35(51.1 \%)$ male patients. Of the 68 patients, $45(66.18 \%)$ and $23(33.82 \%)$ were categorized into non-elderly group and elderly group, as shown in Table 1. In total, $62(91.18 \%)$ patients had contact history. The most common symptoms in both groups were fever and cough.

The CT and laboratory tests of patients on admission were shown in Table 2. Most patients showed multiple lobe infection in both two groups, and no significant difference between this two groups $(\mathrm{P}=0.291)$. The red blood cell count $(3.98 \times 1012 / \mathrm{L})$ and hemoglobin $(122 \mathrm{~g} / \mathrm{L})$ in the elderly group were lower than those in non-elderly group $(4.64 \times 1012 / \mathrm{L}$ and $138 \mathrm{~g} / \mathrm{L}$ respectively). The $\mathrm{C}$-reactive protein in the elderly group was higher than that in the young group (23.49 VS $9.93 \mathrm{mg} / \mathrm{L}$, $P=0.047)$, but there was no significant difference in the procalcitonin between the two groups.

$82.6 \%$ of the elderly patients showed a decrease in CD8+ lymphocyte count, which was much higher than that of in nonelderly group $(48.9 \%), \mathrm{P}=0.009 .77 .8 \%$ of patients showed the decrease of B lymphocyte in elderly group, which was also higher than that in the non-elderly group $(44.8 \%)(\mathrm{P}=0.036)$. However, there was no significant difference in cell counts and rates of lymphocyte subsets and NK cells between the two groups, as shown in Table 3. 
Table 2

CT and laboratory results of COVID-19 patients

\begin{tabular}{|c|c|c|c|}
\hline Characteristics & Non-elderly patients & Elderly patients & $P$ value \\
\hline CT results & & & 0.291 \\
\hline Multiple lobe lesion & $35(77.8 \%)$ & $22(95.7 \%)$ & \\
\hline Right lobe lesion & $7(15.6 \%)$ & $1(4.3 \%)$ & \\
\hline Left lobe lesion & $2(4.4 \%)$ & $0(0 \%)$ & \\
\hline Normal & $1(2.2 \%)$ & $0(0 \%)$ & \\
\hline \multicolumn{4}{|l|}{ Laboratory indicators at admission } \\
\hline Leucocytes, $\times 10^{9}$ per $\mathrm{L}$ & $5.37(4.06-7.23)$ & $5.86(4.32-7.54)$ & 0.841 \\
\hline Neutrophil count, $\times 10^{9}$ per $\mathrm{L}$ & $3.26(2.64-5.24)$ & $4.19(2.40-5.38)$ & 0.795 \\
\hline Lymphocyte count, $\times 10^{9}$ per $\mathrm{L}$ & $1.05(0.65-1.62)$ & $0.90(0.51-1.46)$ & 0.444 \\
\hline Neutrophils, \% & $69.50(61.55-79.45)$ & $74.10(67.00-80.30)$ & 0.437 \\
\hline Lymphocytes, \% & $22.40(14.80-27.85)$ & $17.00(11.10-26.70)$ & 0.396 \\
\hline Red blood cell count, $\times 10^{12}$ per $\mathrm{L}$ & $4.64(4.15-4.99)$ & $3.98(3.56-4.41)$ & 0.001 \\
\hline Haemoglobin, $g / L$ & $138(126-147)$ & $122(103-136)$ & 0.002 \\
\hline Platelet count, $\times 10^{9}$ per $\mathrm{L}$ & $175(121-225)$ & $154(111-239)$ & 0.382 \\
\hline Albumin, g/L & $42.90(37.75-46.10)$ & $36(32.95-40.93)$ & 0.001 \\
\hline Alanine aminotransferase, $\mathrm{U} / \mathrm{L}$ & $27(16-41)$ & $19(15-24)$ & 0.082 \\
\hline Glutamyltransferase, U/L & $27(22-33.5)$ & $30(23-38)$ & 0.479 \\
\hline Total bilirubin, umol/L & $7.60(5.25-14.80)$ & $6.45(3.65-8.13)$ & 0.094 \\
\hline Lactate dehydrogenase, $\mathrm{U} / \mathrm{L}$ & $224(200.5-274)$ & $241(205-296)$ & 0.479 \\
\hline Creatine kinase isoenzymes, $\mathrm{U} / \mathrm{L}$ & $12(9-17)$ & $11(9-17)$ & 0.862 \\
\hline CD3 Count, cells/ul & $666(335.5-1022)$ & $460(318-721)$ & 0.126 \\
\hline CD4 Count, cells/ul & $396(180-517)$ & $313(178-387)$ & 0.270 \\
\hline CD8 Count, cells/ul & $242(137-334)$ & $192(111-219)$ & 0.066 \\
\hline CD3 Percent & $72(63-78)$ & $69(66-75)$ & 0.131 \\
\hline CD4 Percent & $38(31-46)$ & $39(34-45)$ & 0.186 \\
\hline CD8 Percent & $25(22-32)$ & $22(17-30)$ & 0.058 \\
\hline $\mathrm{CD} 4 / \mathrm{CD} 8$ rate & $1.48(1.08-1.91)$ & $1.79(1.24-2.40)$ & 0.126 \\
\hline B Count, cells/ul & $93(59-140)$ & $68.50(46.75-93.75)$ & 0.073 \\
\hline NK Count, cells/ul & $116(59-159.5)$ & $103(53-166.5)$ & 0.810 \\
\hline B Percent & $11.37(9.10-15.47)$ & $9.80(7.42-12.32)$ & 0.118 \\
\hline NK Percent & $13.76(7.71-18.91)$ & $15.57(10.87-22.24)$ & 0.143 \\
\hline Procalcitonin, ng/mL & $0.023(0.019-0.044)$ & $0.028(0.028-0.055)$ & 0.664 \\
\hline C-reactive protein, $\mathrm{mg} / \mathrm{L}$ & $9.93(4.22-22.95)$ & $23.49(6.95-57.94)$ & 0.047 \\
\hline Plasma lactic acid, $\mathrm{mmol} / \mathrm{L}$ & $1.62(1.30-2.13)$ & $1.49(1.20-1.81)$ & 0.172 \\
\hline
\end{tabular}

Comorbidities and the prognosis of elderly patients with COVID-19

The comorbidity of patients was shown in Table 1 . Compared with non-elderly patients, old patients were more likely to combine with other basic diseases before infection of COVID-19 (P = 0.017). 13 (56.5\%) elderly patients combined with atherosclerotic cardiovascular disease, and the proportion was higher than that in the non-elderly group (9 $(20.0 \%), \mathrm{P}=$ $0.005)$. The proportion of patients with hypertension was higher in elderly group than in non-elderly group $(43.5 \%$ and $8.9 \%$, respectively, $\mathrm{P}=0.003)$. Five patients $(21.7 \%)$ in the elderly group had chronic pulmonary disease, but no in the non-elderly 
Table 3

Abnormal laboratory results in two groups of COVID-19 patients

\begin{tabular}{|c|c|c|c|}
\hline Characteristics & Non-elderly patients & Elderly patients & P value \\
\hline Leucocytes $\left(\times 10^{9}\right.$ per L; normal range 3.5-9.5) & & & 0.584 \\
\hline Increased & $7(15.6 \%)$ & $3(13.0 \%)$ & \\
\hline Decreased & $4(8.9 \%)$ & $4(17.4 \%)$ & \\
\hline Neutrophils ( $\times 10^{9}$ per L; normal range $2-7$ ) & & & 0.961 \\
\hline Increased & $7(15.6 \%)$ & $3(13.0 \%)$ & \\
\hline Lymphocytes $\left(\times 10^{9}\right.$ per L; normal range $\left.0.8-4\right)$ & & & 0.422 \\
\hline Decreased & $14(31.1 \%)$ & $10(43.5 \%)$ & \\
\hline CD3 Count (cells/ul; normal range 770-2041) & & & 0.114 \\
\hline Decreased & $26(57.8 \%)$ & $18(78.3 \%)$ & \\
\hline CD4 Count (cells/ul; normal range 414-1123) & & & 0.065 \\
\hline Decreased & $24(53.3 \%)$ & $18(78.3 \%)$ & \\
\hline CD8 Count (cells/ul; normal range 238-874) & & & 0.009 \\
\hline Decreased & $22(48.9 \%)$ & $19(82.6 \%)$ & \\
\hline B Count (cells/ul; normal range 90-560) & & & 0.036 \\
\hline Decreased & $13(44.8 \%)$ & $14(77.8 \%)$ & \\
\hline NK Count (cells/ul; normal range 150-1100) & & & 1.000 \\
\hline Decreased & $21(72.4 \%)$ & $13(72.2 \%)$ & \\
\hline C-reactive protein (mg/L; normal range $0-5$ ) & & & 0.389 \\
\hline Increased & $32(71.1 \%)$ & $18(81.8 \%)$ & \\
\hline Alanine aminotransferase (U/L; normal range $0-37)$ & & & 0.067 \\
\hline Increased & $14(31.1 \%)$ & $2(9.1 \%)$ & \\
\hline Aspartate aminotransferase (U/L; normal range $0-37$ ) & & & 0.745 \\
\hline Increased & $8(17.8 \%)$ & $5(22.7 \%)$ & \\
\hline Albumin (g/L; normal range $35-55)$ & & & 0.052 \\
\hline Decreased & $6(13.3 \%)$ & $8(36.4 \%)$ & \\
\hline Lactic dehydrogenase & & & 0.594 \\
\hline Increased & $16(35.6 \%)$ & $10(45.5 \%)$ & \\
\hline Hydroxybutyrate Dehydrogenase & & & 0.193 \\
\hline Increased & $18(40.0 \%)$ & $13(59.1 \%)$ & \\
\hline Creatine jubase & & & 0.745 \\
\hline Increased & $8(17.8 \%)$ & $5(22.7 \%)$ & \\
\hline
\end{tabular}

group $(\mathrm{P}=0.003)$.

The proportion of severe cases was higher in elderly group than that in non-elderly group $(73.9 \%$ and $42.2 \%$, respectively, $\mathrm{P}=0.012$ ). During hospitalization, the proportion of elderly patients with respiratory failure was higher than that of in non-elderly patients $(21.7 \%$ and $4.4 \%$, respectively, $\mathrm{P}=0.039)$. Shock was also more common in older patients than non-elderly patients $(21.7 \%$ vs $2.2 \%, \mathrm{P}=0.015)$. And of the 6 patients with shock, 5 had a history of atherosclerotic cardiovascular disease. The proportion of elderly patients requiring mechanical ventilation during treatment was higher than that of younger patients $(30.4 \%, 8.9 \%$, respectively, $\mathrm{P}=0.020)$. As shown in table 4 , the prognosis of the elderly patients was worse than that of the non-elderly group $(\mathrm{P}=0.006)$. All 3 deaths were elderly patients with underlying diseases before admission. The level of C-reactive protein of these dead patients was significantly increased and the cell counts of CD3+, CD4+, and CD8+ T lymphocytes, B lymphocytes and NK cells were significantly decreased at admission, as shown in supplementary table 1 . 
EFFECTS OF COMORBIDITIES ON THE ELDERLY PATIENTS WITH COVID-19

Table 4

Prognosis of COVID-19 patients

\begin{tabular}{lccc}
\hline Characteristics & Non-elderly patients & Elderly patients & P value \\
\hline Severe cases & $19(42.2 \%)$ & $17(73.9 \%)$ & 0.012 \\
Complications & & & 0.274 \\
Acute liver and kidney injury & $17(37.8 \%)$ & $5(21.7 \%)$ & 0.035 \\
Coagulation function abnormal & $0(0 \%)$ & $3(13.0 \%)$ & 0.039 \\
Respiratory failure & $2(4.4 \%)$ & $5(21.7 \%)$ & 0.015 \\
Shock & $1(2.2 \%)$ & $5(21.7 \%)$ & 0.020 \\
Oxygen support & & & $11(47.8 \%)$ \\
Low-flow nasal cannula & $36(80.0 \%)$ & $5(21.7 \%)$ & 0.006 \\
High-flow nasal cannula & $5(11.1 \%)$ & $7(30.4 \%)$ & \\
Mechanical & $4(8.9 \%)$ & & $13(56.5 \%)$ \\
Prognosis & & $0(0.0 \%)$ & \\
Discharge & $36(80.0 \%)$ & $7(30.4 \%)$ & \\
Hospital readmission & $4(8.9 \%)$ & $3(13.0 \%)$ & 0.711 \\
Hospitalisation & $5(11.1 \%)$ & $7(2-8)$ & 0.915 \\
Death & $0(0.0 \%)$ & $10(8-14)$ & \\
Days from illness onset to hospital admission & $7(4-11.5)$ & $9(7-12)$ & \\
Hospitalization days & & & \\
\hline
\end{tabular}

\section{Discussion}

This study collected the clinical information of 68 patients with COVID-19 infection who hospitalized in Public Health Clinical Center of Chengdu, Sichuan. The clinical characteristics of elderly patients with COVID-19 were descripted by compared with non-elderly patients.

We observed more patients with COVID-19 were men which was same as the results of previous study (13-15). The proportion of elderly patients was $33.82 \%$, which was similar to other studies $(16,15)$. In our study, the most common symptom were fever $(78.3 \%)$ and cough $(60.9 \%)$ in elderly patients, which was similar to other researches (17-19). A previous study found that the incidence of multilobe lesions in elderly patients was significantly higher than in non-elderly patients (16). We also observed the higher incidence of multilobe lesions in elderly patients, although no statistically difference.

In this study, the proportion of patients with decreased leucocytes count was $11.8 \%$, lymphocytes $35.3 \%$, lower than that of in a previous study ( $33.7 \%$ and $83.2 \%$, respectively) (20). The proportion of patients with a decreased number of CD8+ T lymphocytes and B lymphocytes in elderly patients was significantly higher than that in non-elderly group, suggesting that elderly patients were more likely to indicate low immune function. The previous study observed that the acute phase of SARS in humans was associated with a severe reduction in the number of $\mathrm{T}$ cells in the blood (21).The level of C-reactive protein in elderly patients was significantly higher than that in the non-elderly group, which was consistent with previous study and similar to MERS-CoV infection $(22,16)$.

We found that the prognosis of patients with COVID-19 in elderly patients was worse, which was in accordance with the results of other studies $(23,24,16)$. All 3 dead cases were elderly patients, and had multi-system disease before infected by COVID-19, with decreased umber of T lymphocyte subsets, B lymphocytes and NK cells. An investigation of 463 patients with COVID-19 disease revealed the decreased amount of total lymphocytes, $\mathrm{T}$ lymphocyte subsets in the severe type patients (25). Therefore, patients with COVID-19 should actively deal with their comorbidities, prevent bacterial infection and strengthen immune support treatment.

This study found that older patients with COVID-19 indicated relatively higher proportion of comorbidities than non-elderly patients, and the most common comorbidities were atherosclerotic cardiovascular disease $(56.5 \%)$, hypertension $(43.5 \%)$ and chronic pulmonary disease $(21.7 \%)$, which was consistent with other studies $(26,15)$. These multiple disease coexisting in elderly patients affected each other and leaded to complicated and complex diseases. Severe patients were significantly more in elderly patients than non-elderly patients, which was in accordance with previous researches $(27,19)$. Comorbidities was a risk factor for severe cases $(\mathrm{OR}=2.95$, $\mathrm{P}=0.035)$. We also observed that elderly patients indicated relatively higher proportion of complications, such as shock 


\section{THE JOURNAL OF NUTRITION, HEALTH \& AGING}

$(21.7 \%)$. And of the 6 patients with shock, 5 had a history of atherosclerotic cardiovascular disease. Therefore, actively dealing with the complications may improve the prognosis of patients.

The co-occurrence of chronic diseases in the elderly is a common problem in the field of global public health (7). It was reported that more than half of the elderly in developed countries had more than three chronic diseases, meaning an individual suffers from two or more diseases with different pathology and no mutual dependence at the same time $(8,9)$. Studies in China such as Beijing and Shanghai suggest that more than 70 percent of elderly people in the community have two or more chronic diseases $(10,11)$. Compared with patients with a single disease, the hospitalization rate and fatality rate of patients with comorbidities are higher, and the clinical prognosis is significantly lower. A cohort study showed that comorbidities were independent predictors of clinical prognosis in patients with cardiovascular disease (28). Comorbidities make medical decisions more complex and difficult. And, comorbidities often involve multiple medications, and the interactions between drugs and diseases often lead to worse final efficacy, worse prognosis, more adverse reactions and more medical costs (28).

At present, there are no guidelines for comorbidity management. In 2012, the American geriatrics society organized an expert group to formulate the guiding principles for clinical management of comorbidity in the elderly, such as considering the complexity and feasibility of the treatment plan; optimize the treatment plan to choose the one that benefits the most, does the least damage and can improve the quality of life, and carry on the elaboration explanation one by one (9). Doctors should be reminded that the treatment of comorbidities should emphasize patient-centered treatment, considering the whole patient and giving the most appropriate individual treatment.

\section{Limitations}

There are some limitations in our study. First, not all COVID-19 cases in Sichuan were enrolled in this study, but only patients admitted to Public Health Clinical Center of Chengdu. And the sample size of our study is relatively small. A study which cover wide population is needed to get more accurate results. Secondly, more detailed patient information was not analyzed, especially different treatment methods and their outcomes.

\section{Conclusions}

In this study we observed elderly patients infected with COVID-19 had a high proportion of severe cases and comorbidities, more likely to show low immune function and indicated higher proportion of complications during the course of COVID-19 infection. All dead cases were elderly patients and with low immunity and comorbidities. Therefore, we should pay more attention to elderly patients, especially their comorbidities, and try to give the most appropriate individual treatment for older patients with COVID-19 infection.

Funding: The work for this report was funded by Subject of Cadre Health Care (GB2014003).

Conflict of Interest/Competing interests: The authors have no conflicts of interest.

Ethics approval/ Informed consent: Our study was approved by the ethics committee of West China hospital (No.2020/430) and the written informed consent was waived.

Availability of data and material: The datasets used and/or analyzed during the current study are available from the corresponding author on reasonable request.

Author Contributions: Dai Shuiping and Wu Jinhui made substantial contributions to conception and design. Dai Shuiping and Zhao Xuan made substantial contributions to acquisition of data, analysis and interpretation of data. All authors participated in drafting the article or revising it critically for important intellectual content; and gave final approval of the version to be submitted.

Open Access: This article is distributed under the terms of the Creative Commons Attribution 4.0 International License (http://creativecommons.org/licenses/by/4.0/), which permits use, duplication, adaptation, distribution and reproduction in any medium or format, as long as you give appropriate credit to the original author(s) and the source, provide a link to the Creative Commons license and indicate if changes were made.

\section{References}

1. Lu H, Stratton CW, Tang YW. Outbreak of pneumonia of unknown etiology in Wuhan, China: The mystery and the miracle. 2020;92 (4):401-402. doi:10.1002/ jmv. 25678

2. World Health Organization, 2020. Director-General's remarks at the media briefing on 2019-nCoV on 11 February 2020 [EB/OL]. (2020-02-13) [2020-02-11]. https://www who.int/dg/speeches/detail/who-director-general-s-remarks-at-the-media-briefingon2019-ncov-on-11-february-2020.

3. Rasmussen SH, Andersen-Ranberg K, Thinggaard M, Jeune B, Skytthe A, Christiansen L, Vaupel JW, McGue M, Christensen K. Cohort Profile: The 1895 , 1905, 1910 and 1915 Danish Birth Cohort Studies - secular trends in the health and functioning of the very old. Int J Epidemiol 2017;46 (6):1746-1746j. doi:10.1093/ije/ dyx053

4. Kingston A, Robinson L, Booth H, Knapp M, Jagger C. Projections of multi-morbidity in the older population in England to 2035: estimates from the Population Ageing and Care Simulation (PACSim) model. Age Ageing 2018;47 (3):374-380. doi:10.1093/ ageing/afx 201

5. Sun P, Lu X, Xu C, Sun W, Pan B. Understanding of COVID-19 based on current evidence. 2020 doi: 10.1002/jmv.25722

6. Verity R, Okell LC, Dorigatti I, Winskill P, Whittaker C, Imai N, Cuomo-Dannenburg G, Thompson H, Walker PGT, Fu H, Dighe A, Griffin JT, Baguelin M, Bhatia S, Boonyasiri A, Cori A, Cucunubá Z, FitzJohn R, Gaythorpe K, Green W, Hamlet A, Hinsley W, Laydon D, Nedjati-Gilani G, Riley S, van Elsland S, Volz E, Wang H, Wang Y, Xi X, Donnelly CA, Ghani AC, Ferguson NM. Estimates of the severity of coronavirus disease 2019: a model-based analysis. The Lancet Infectious Diseases. 2010;doi:10.1016/s1473-3099(20)30243-7

7. Coventry P, Lovell K, Dickens C, Bower P, Chew-Graham C, McElvenny D, Hann M, Cherrington A, Garrett C, Gibbons CJ, Baguley C, Roughley K, Adeyemi I, Reeves D, Waheed W, Gask L. Integrated primary care for patients with mental and physical multimorbidity: cluster randomised controlled trial of collaborative care for patients with depression comorbid with diabetes or cardiovascular disease. BMJ 2015;350:h638. doi:10.1136/bmj.h638

8. Boyd C M, Fortin M. Future of multimorbidity research: how should understanding of multimorbidity inform health system design? [J] Public Health Rev, 2010;32(2): 451 474. doi:10. 1007 /BF03391611.

9. Guiding principles for the care of older adults with multimorbidity: an approach for clinicians: American Geriatrics Society Expert Panel on the Care of Older Adult with Multimorbidity. J Am Geriatr Soc 2012;60 (10):E1-e25. doi:10.1111/j.15325415.2012.04188.x

10. Zhang K K, Zhu M L, Liu X H, et al. Investigation of multimorbidity and geriatric syndromes in the elder people in Beijing communities [J] Chinese Journal of Practice Internation Medicine, 2016;36(5): 419-421. doi: 10.7504 / nk2016040601.

11. Wang J F, Wang Y Q, Bao Z J, et al. Epidemiological analysis on chronic disease and multimorbidity in middle and elderly health-examination population in Shanghai 


\section{EFFECTS OF COMORBIDITIES ON THE ELDERLY PATIENTS WITH COVID-19}

city [J]. Geriatr\&Health Care, 2016;22(2): 116-120. doi: 10. 3969/j.issn.10088296.2016.02.17.

12. World Health Organization. Clinical management of severe acute respiratory infection when Novel coronavirus (nCoV) infection is suspected: interim guidance. Jan 11 , 2020. https://www.who.int/internalpublications-detail/clinical-management-of-severeacute-respiratoryinfection-when-novel-coronavirus-(ncov)-infection-is-suspected (accessed Jan 20, 2020).

13. Backer JA, Klinkenberg D, Wallinga J. Incubation period of 2019 novel coronavirus (2019-nCoV) infections among travellers from Wuhan, China, 20-28 January 2020. Euro Surveill 2020;25 (5). doi:10.2807/1560-7917.es.2020.25.5.2000062

14. Li Q, Guan X, Wu P, Wang X, Zhou L, Tong Y, Ren R, Leung KSM, Lau EHY, Wong JY, Xing X, Xiang N, Wu Y, Li C, Chen Q, Li D, Liu T, Zhao J, Liu M, Tu W, Chen C, Jin L, Yang R, Wang Q, Zhou S, Wang R, Liu H, Luo Y, Liu Y, Shao G, Li H, Tao Z, Yang Y, Deng Z, Liu B, Ma Z, Zhang Y, Shi G, Lam TTY, Wu JT, Gao GF, Cowling BJ. Early Transmission Dynamics in Wuhan, China, of Novel CoronavirusInfected Pneumonia. 2020;382 (13):1199-1207. doi:10.1056/NEJMoa2001316

15. Chen N, Zhou M, Dong X, Qu J, Gong F, Han Y, Qiu Y, Wang J, Liu Y, Wei Y, Xia J, Yu T, Zhang X, Zhang L. Epidemiological and clinical characteristics of 99 cases of 2019 novel coronavirus pneumonia in Wuhan, China: a descriptive study. Lancet 2020;395 (10223):507-513. doi:10.1016/s0140-6736(20)30211-7

16. Liu K, Chen Y, Lin R, Han K. Clinical features of COVID-19 in elderly patients: A comparison with young and middle-aged patients. J Infect. 2020;doi:10.1016/j. jinf.2020.03.005

17. Guan WJ, Ni ZY, Hu Y, Liang WH, Ou CQ, He JX, Liu L, Shan H, Lei CL, Hui DSC, Du B, Li LJ, Zeng G, Yuen KY, Chen RC, Tang CL, Wang T, Chen PY, Xiang J, Li SY, Wang JL, Liang ZJ, Peng YX, Wei L, Liu Y, Hu YH, Peng P, Wang JM, Liu JY, Chen Z, Li G, Zheng ZJ, Qiu SQ, Luo J, Ye CJ, Zhu SY, Zhong NS. Clinical Characteristics of Coronavirus Disease 2019 in China. N Engl J Med 2020;382 (18):1708-1720. doi:10.1056/NEJMoa2002032

18. Deng SQ, Peng HJ. Characteristics of and Public Health Responses to the Coronavirus Disease 2019 Outbreak in China. 2020;9 (2). doi:10.3390/jcm9020575

19. Niu S, Tian S, Lou J, Kang X, Zhang L, Lian H, Zhang J. Clinical characteristics of older patients infected with COVID-19: A descriptive study. Arch Gerontol Geriatr 2020;89:104058. doi:10.1016/j.archger.2020.104058

20. Guan WJ, Ni ZY, Hu Y, Liang WH, Ou CQ, He JX, Liu L, Shan H, Lei CL, Hui DSC, Du B, Li LJ, Zeng G, Yuen KY, Chen RC, Tang CL, Wang T, Chen PY, Xiang J, L SY, Wang JL, Liang ZJ, Peng YX, Wei L, Liu Y, Hu YH, Peng P, Wang JM, Liu JY, Chen Z, Li G, Zheng ZJ, Qiu SQ, Luo J, Ye CJ, Zhu SY, Zhong NS, China Medical Treatment Expert Group for C. Clinical Characteristics of Coronavirus Disease 2019 in China. N Engl J Med. 2020; doi:10.1056/NEJMoa2002032
21. Channappanavar R, Zhao J, Perlman S. T cell-mediated immune response to respiratory coronaviruses. Immunol Res 2014;59 (1-3):118-128. doi:10.1007/s12026014-8534-z

22. Peeri NC, Shrestha N, Rahman MS, Zaki R, Tan Z, Bibi S, Baghbanzadeh M, Aghamohammadi N, Zhang W, Haque U. The SARS, MERS and novel coronavirus (COVID-19) epidemics, the newest and biggest global health threats: what lessons have we learned? Int J Epidemiol. 2020;doi:10.1093/ije/dyaa033

23. Liu W, Tao ZW, Wang L, Yuan ML, Liu K, Zhou L, Wei S, Deng Y, Liu J, Liu HG, Yang M, Hu Y. Analysis of factors associated with disease outcomes in hospitalized patients with 2019 novel coronavirus disease. Chin Med J (Engl) 2020;133 (9):10321038. doi: $10.1097 / \mathrm{cm} 9.0000000000000775$

24. Xu XW, Wu XX, Jiang XG, Xu KJ, Ying LJ, Ma CL, Li SB, Wang HY, Zhang S, Gao HN, Sheng JF, Cai HL, Qiu YQ, Li LJ. Clinical findings in a group of patients infected with the 2019 novel coronavirus (SARS-Cov-2) outside of Wuhan, China: retrospective case series. 368:m606. doi:10.1136/bmj.m606, 2020

25. Yao Z, Zheng Z, Wu K, Junhua Z. Immune environment modulation in pneumonia patients caused by coronavirus: SARS-CoV, MERS-CoV and SARS-CoV-2. Aging (Albany NY) 12. doi:10.18632/aging.103101, 2020

26. Yang W, Cao Q, Qin L, Wang X, Cheng Z, Pan A, Dai J, Sun Q, Zhao F, Qu J, Yan F. Clinical characteristics and imaging manifestations of the 2019 novel coronavirus disease (COVID-19):A multi-center study in Wenzhou city, Zhejiang, China. J Infect 2020;80 (4):388-393. doi:10.1016/j.jinf.2020.02.016

27. Chan JF, Yuan S, Kok KH, To KK, Chu H, Yang J, Xing F, Liu J, Yip CC, Poon RW, Tsoi HW, Lo SK, Chan KH, Poon VK, Chan WM, Ip JD, Cai JP, Cheng VC, Chen H, Hui CK, Yuen KY. A familial cluster of pneumonia associated with the 2019 nove coronavirus indicating person-to-person transmission: a study of a family cluster. Lancet 2020;395 (10223):514-523. doi:10.1016/s0140-6736(20)30154-9

28. Global, regional, and national incidence, prevalence, and years lived with disability for 301 acute and chronic diseases and injuries in 188 countries, 1990-2013: a systematic analysis for the Global Burden of Disease Study 2013. Lancet 2015;386 (9995):743 800. doi:10.1016/s0140-6736(15)60692-4 